\title{
Helicobacter Pylori Infection is Associated with Portal Hypertensive Gastropathy in Patients with Liver Cirrhosis
}

\author{
Naglaa El-Toukhy ${ }^{1}$, Lubna Omar El-Farouk ${ }^{2}$, Mona Youssef ${ }^{3}$ \\ ${ }^{1}$ Department of Hepatology, Gastroenterology and Infectious Diseases, Faculty of \\ Medicine, Benha University, Egypt. \\ ${ }^{2}$ Department of Pathology, Faculty of Medicine, Ain Shams University, Egypt. \\ ${ }^{3}$ Department of Hepatology, Gastroenterology and infectious Diseases, Benha \\ Teaching Hospital, Egypt.
}

Corresponding Author Mona Youssef

Mobile:

$+201225529030$

E mail:

mona.yussef@yahoo.c om.

Key words:

Liver cirrhosis, Portal hypertensive gastropathy, Helicobacter pylori
Background and study aims: Portal hypertensive gastropathy (PHG) is a complication of portal hypertension in patients with liver cirrhosis, and it is considered one of the causes of upper gastrointestinal bleeding. Helicobacter pylori (H. Pylori) is one of the most common pathogenic organism worldwide because it infects $50 \%$ of the population all over the world. The role of $\mathrm{H}$. Pylori infection in the development of PHG and its severity is controversial. The aim of this study is to determine the frequency of H. pylori infection in cirrhotic patients with $\mathrm{PHG}$, and to find out the possible association of H.pylori infection with PHG severity.

Method: This study was carried out on 90 patient with cirrhotic liver. Patients were divided into two groups according to the presence or absence of PHG diagnosed by upper endoscopy. Child's Pugh score,
MELD, uMELD and detection of H.Pylori by histopathological examination were done for all patients.

Results: The studied patients 47 were males and 43 were females their mean age was $51.96 \pm 7.02$ years (ranging between 38-66 years). H.Pylori infection was significantly more frequent in patients with PHG than patients without PHG (P= 0.001). H.Pylori infection was significantly more frequent in patients with severe PHG than those with mild PHG $\quad(\mathrm{P}=0.012)$. By multi-variant analysis, splenomegaly, presence of esophageal varices, gastric varices and $\mathrm{H}$. Pylori infection were independent predictors for PHG presence.

Conclusion: H. Pylori infection could be an independent predictor for $\mathrm{PHG}$ development and associated with its severity.

\section{INTRODUCTION}

Portal hypertensive gastropathy (PHG) is a frequent finding diagnosed by upper endoscopy in cirrhotic patients in the form of mosaic pattern gastric mucosa and may be associated with red spots. PHG may cause upper gastrointestinal bleeding and anemia [1]. The prevalence of PHG in patients with cirrhosis ranges widely $20 \%$ - 98\% which was reported by many studies as multiple various classifications and definitions were applied [2].

Helicobacter pylori (H. pylori) infection has a high prevalence especially in low socioeconomic class of developing countries, it is considered as one of the causes of peptic erosions and ulcers [3].

In cirrhotic patients $H$. pylori infection is considered as a leading cause of non-variceal bleeding [4].

Moreover, Abdul Sattar et al. reported that there was a significant relation between $\mathrm{H}$. pylori infection and PHG in cirrhotic patients and also, the severity of PHG [5]. Hence, the aim of this study to determine the frequency of $\mathrm{H}$. pylori infection in cirrhotic patients with PHG and to detect the possible association of $\mathrm{H}$. pylori infection with PHG severity. 


\section{PATIENTS AND METHODS}

The current study was carried out on 90 patients with liver cirrhosis, divided into two groups according to presence or absence of PHG diagnosed by upper endoscopy, these patients attended or admitted to Hepatology and Gastroenterology Department at Nasser Institute Hospital and Department of Hepatology, Gastroenterology and Infectious diseases in Benha University Hospital, within the period between November 2018 and April 2019, after approval of the scientific committee of faculty of Medicine .

Patients with cirrhosis diagnosed by clinical manifestations, laboratory investigations and ultrasonography, which may reveal (surface nodularity, coarse echopattern of the liver, rarified hepatic central vein, enlarged caudate lobe, ascites, splenomegaly and collateralls) [5] Patients were classified according to presence or absence of portal hypertensive gastropathy which was diagnosed by upper gastrointestinal endoscopy.

\section{Methods}

\section{Full history taking:}

Age, sex, smoking, occupation and residence, abdominal pain, abdominal enlargement, Jaundice, hepatic encephalopathy, blood transfusion and history of previous attacks of bleeding.

\section{Thorough clinical examination:}

General examination: Blood pressure, pulse, temperature, Jaundice, ecchymosis, clubbing, palmar erythema, flapping tremors and lower limb edema and abdominal examination: Organomegaly (hepatomegaly and splenomegaly) and ascites.

\section{Laboratory investigations including:}

Fasting blood sugar (FBS), complete blood count (CBC), aspartate aminotransferase (AST), alanine aminotransferase (ALT), alkaline phosphatase (ALP), serum bilirubin (total, direct), serum albumin, prothrombin time (P.T), international normalized ratio (INR) and serum creatinine.

The severity of liver disease assessed by Modified Child's Pugh score[6]. MELD score (Model for End Stage Liver Disease) [7]. UMELD score (Updated Model for End Stage Liver Disease) [8].

\section{Pelvi-abdominal Ultrasonography:}

This was done using (LOGIC P6 PRO, GE Healthcare, Korea) with a convex probe $(3.75$ MHZ).

- Evaluation of liver ( size, echo pattern, portal vein and presence of focal lesion).

- Evaluation of spleen ( size and echo pattern).

- The presence of ascites .

\section{Esophagogastroduodendoscopy (EGD):}

This was done using disinfected upper gastrointestinal video scope (OLYMPUS Evis EXERAП CLV-180, Tokyo, Japan) after good preparation of the patient.

- Esophageal varices ( E.V) were classified as :

- Small (E.V): defined as varices that flatten with insufflation or minimally protrude into the esophageal lumen.

- Large (E.V): defined as varices that protrude into the esophageal lumen and touch each other, or fill at least $50 \%$ of the esophageal lumen.

The grading (I-IV) classification:

- Grades I and II were reclassified as small.

- Grades III and IV were reclassified as large for this study.

- Portal hypertensive gastropathy (PHG): were reported according to Modified grading system proposed by the Baveno III meeting ( Baveno, Italy(2000)on portal hypertension [9].

- PHG is mild when a pink mosaic-like mucosal pattern with no red signs or black brown spots.

- PHG is severe when the mosaic-like mucosal pattern is red and superimposed by any red sign (red point lesions and/or cherry red spots) or black brown spots.

- Presence or absence of gastric varices.

- Signs suggesting H. pylori infection e.g inflammation, erosions and ulcers.

\section{Histopathological examination of $\mathrm{H}$. pylori:}

Routinely processed, Formalin-fixed, paraffinembedded gastric antral tissues were used in this study and cut into three to four microns thick serial sections, then mounted on grease-free 
slides and subjected to H\&E (HaematoxylinEosin) stain:

Examined for the presence of $\mathrm{H}$. pylori (Gram negative spiral to comma-shaped organisms, sometimes cocci).

\section{Statistical Analysis}

IBM SPSS statistics (V. 25.0, IBM Corp., USA, 2017-2018) was used for data analysis. Data were expressed as Mean \pm SD for quantitative parametric measures in addition to both number and percentage for categorized data.

\section{The following tests were done:}

Comparison between two independent mean groups for parametric data using Student t-test. Chi-square test to study the association between each 2 variables or comparison between 2 independent groups regarding the categorized data.

The probability of error at 0.05 was considered significant, while at 0.01 and 0.001 were highly significant. Logistic Multi-Regression analysis was used to search for a panel (independent parameters) that can predict the target parameter (dependent variable). By using logistic stepwise multi-regression analysis, we can get the most sensitive ones that predict the dependent variable. They can be sorted according to their sensitivity to discriminate according to their $\mathrm{p}$-values.

\section{RESULTS}

Table (1) showed the demographic features of the studied patients, 47 were males $(52.5 \%)$ and 43 were females $(47.5 \%)$. Their mean age was $51.96 \pm 7.02$ years (ranging from 38 to 66 years).The patients were classified into two groups according to presence or absence of PHG.

Most of the patients with PHG were Child B and Child $\mathrm{C}$, in contrast to most patients without PHG who were Child A as shown in table (2). MELD and UMELD scores were higher in patients with PHG with statistically significant difference in comparison to ptients without PHG, as present in table (3) as well.

Table (4) showed that ascites, splenomegaly and dilated portal vein were significantly higher in patients with PHG than patients without PHG.

Helicobacter pylori (H. pylori) infection was significantly more frequent in cirrhotic patients with PHG than those without PHG and more frequent in patients with severe PHG than patients with mild PHG as shown in table (5\&6).

By multi-variant analysis, splenomegaly, presence of esophageal varices, gastric varices and $\mathrm{H}$. Pylori infection were independent predictors for PHG presence.

Table (1): Demographic features of the studied patients:

\begin{tabular}{|c|c|c|c|c|c|c|c|}
\hline & \multicolumn{2}{|c|}{$\begin{array}{l}\text { Without PHG } \\
\quad(n=45)\end{array}$} & \multicolumn{2}{|c|}{$\begin{array}{c}\text { With PHG } \\
(\mathrm{n}=45)\end{array}$} & \multicolumn{2}{|c|}{$\begin{array}{c}\text { Total } \\
(\mathbf{n}=90)\end{array}$} & \multirow[t]{2}{*}{ P-value } \\
\hline & No. & $\%$ & No. & $\%$ & No. & $\%$ & \\
\hline $\begin{array}{l}\text { Gender } \\
\text { Male } \\
\text { Female }\end{array}$ & $\begin{array}{l}19 \\
26\end{array}$ & $\begin{array}{l}42.2 \\
57.8 \\
\end{array}$ & $\begin{array}{l}28 \\
17 \\
\end{array}$ & $\begin{array}{l}62.2 \\
37.8 \\
\end{array}$ & $\begin{array}{l}47 \\
43\end{array}$ & $\begin{array}{l}52.2 \\
47.8 \\
\end{array}$ & 0.058 \\
\hline $\begin{array}{l}\text { Age (years) } \\
\text { Range } \\
\text { Mean } \pm \text { SD. }\end{array}$ & \multicolumn{2}{|c|}{$\begin{array}{c}38.0-66.0 \\
52.42 \pm 7.753\end{array}$} & \multicolumn{2}{|c|}{$\begin{array}{c}39.0-66.0 \\
55.51 \pm 6.814\end{array}$} & \multicolumn{2}{|c|}{$\begin{array}{c}38.0-66.0 \\
51.96 \pm 7.02\end{array}$} & 0.048 \\
\hline $\begin{array}{l}\text { Urban } \\
\text { Rural }\end{array}$ & $\begin{array}{l}16 \\
29 \\
\end{array}$ & $\begin{array}{l}35.6 \% \\
64.4 \% \\
\end{array}$ & $\begin{array}{ll}12 \\
33\end{array}$ & $\begin{array}{c}26.7 \% \\
73 \% \\
\end{array}$ & $\begin{array}{l}28 \\
62 \\
\end{array}$ & $\begin{array}{l}31 \% \\
69 \% \\
\end{array}$ & 0.362 \\
\hline $\begin{array}{l}\text { Farmer } \\
\text { Non farmer }\end{array}$ & $\frac{4}{41}$ & $\begin{array}{c}8.89 \% \\
91 \%\end{array}$ & $\frac{8}{37}$ & $\begin{array}{l}17.8 \% \\
82.2 \%\end{array}$ & $\frac{12}{78}$ & $\frac{13 \%}{87 \%}$ & 0.215 \\
\hline
\end{tabular}

PHG: portal hypertensive gastropathy, SD: standard deviation. 
Table (2): The severity of liver disease assessed by Child-Pugh Classification among the studied patients.

\begin{tabular}{|l|c|c|c|c|c|}
\hline \multirow{3}{*}{ Child grade } & \multicolumn{2}{|c|}{ Group I Without PHG } & \multicolumn{2}{|c|}{ Group II With PHG } & \multirow{2}{*}{ P-value } \\
\cline { 2 - 5 } & $\mathrm{N}$ & $\%$ & $\mathrm{~N}$ & $\%$ & \\
Child A & 43 & 95.7 & 8 & 17.8 & \multirow{2}{*}{0.000} \\
Child B & 2 & 4.3 & 28 & 62.2 & \\
Child C & 0 & 0 & 9 & 20 & \\
\hline
\end{tabular}

Table(3): The severity of liver disease in patients assessed by MELD and uMELD scores.

\begin{tabular}{|l|c|c|c|c|c|}
\hline \multirow{2}{*}{\multicolumn{1}{c|}{ Parameter }} & \multicolumn{2}{|c|}{ Group I Without PHG } & \multicolumn{2}{c|}{ Group II With PHG } & \multirow{2}{*}{ P-value } \\
\cline { 2 - 5 } & Range & Mean \pm SD & Range & Mean \pm SD & \\
\hline MELD & $8.0-16.0$ & $12.64 \pm 2.28$ & $7.0-23.0$ & $16.56 \pm 4.36$ & 0.000 \\
UMELD & $2.5-4.3$ & $3.15 \pm 0.27$ & $2.7-4.5$ & $3.66 \pm 0.49$ & 0.000 \\
\hline
\end{tabular}

MELD: Model for end stage liver disease, UMELD: Updated Model for end stage liver disease.

Table(4): Abdominal ultrasonographic features of the studied patients.

\begin{tabular}{|c|c|c|c|c|c|}
\hline \multirow[t]{2}{*}{ Parameter } & \multicolumn{2}{|c|}{$\begin{array}{c}\text { Group I Non PHG } \\
n=45\end{array}$} & \multicolumn{2}{|c|}{$\begin{array}{c}\text { Group II PHG } \\
n=45\end{array}$} & \multirow[t]{2}{*}{ P-value } \\
\hline & Range & Mean \pm SD & Range & Mean \pm SD & \\
\hline $\begin{array}{l}\text { Spleen size } \\
\text { (normal: } 12-14 \mathrm{~cm} \text { ) }\end{array}$ & $11-14.06$ & $12.56 \pm 0.92$ & $12-21.5$ & $15.77 \pm 2.39$ & 0.000 \\
\hline $\begin{array}{l}\mathbf{P . V}(\mathrm{cm}) \\
\text { (normal: 1-1.3) }\end{array}$ & $1.06-1.5$ & $1.37 \pm 0.108$ & $1.2-1.8$ & $1.46 \pm 0.282$ & 0.048 \\
\hline & no & $\%$ & No & $\%$ & P-value \\
\hline Ascites & 6 & 13.3 & 34 & 75.5 & 0.000 \\
\hline \begin{tabular}{|l} 
Liver \\
Enlarged \\
Shrunken
\end{tabular} & $\begin{array}{c}2 \\
43\end{array}$ & $\begin{array}{c}4.4 \\
95.5\end{array}$ & $\begin{array}{c}0 \\
45\end{array}$ & $\begin{array}{c}0 \\
100\end{array}$ & 0.153 \\
\hline
\end{tabular}

P.V: portal vein.

Table (5) : Endoscopic features of the studied patients.

\begin{tabular}{|l|c|c|c|c|c|}
\hline \multirow{2}{*}{ Parameter } & \multicolumn{2}{|c|}{$\begin{array}{c}\text { Group I non PHG } \\
\text { no=45 }\end{array}$} & \multicolumn{2}{c|}{$\begin{array}{c}\text { Group II PHG } \\
\text { no=45 }\end{array}$} & \multirow{2}{*}{ P-value } \\
\cline { 2 - 5 } & No & $\%$ & No & $\%$ & \\
\hline Esophageal varices & 6 & 13.33 & 43 & 95.5 & 0.000 \\
Small varices & 4 & 8.88 & 14 & 32.5 & 0.000 \\
Large varices & 2 & 4.4 & 29 & 67.4 & \\
Gastric varices & 1 & 2.22 & 9 & 16.1 & 0.007 \\
PHG grade & 0 & 0 & 25 & 55.6 & \\
Mild & 0 & 0 & 20 & 44.4 & 0.000 \\
Severe & 0 & & & \\
\hline
\end{tabular}

Table (6) : Association between H. pylori and PHG.

\begin{tabular}{|l|c|c|c|c|c|}
\hline \multirow{2}{*}{} & \multicolumn{2}{|c|}{$\begin{array}{c}\text { Without PHG } \\
(\mathbf{n = 4 5})\end{array}$} & \multicolumn{2}{c|}{$\begin{array}{c}\text { With PHG } \\
(\mathbf{n = 4 5})\end{array}$} & \multirow{2}{*}{ P-value } \\
\cline { 2 - 5 } & No. & $\%$ & No. & $\%$ & \\
\hline H. Pylori & & & & & \multirow{2}{*}{0.001} \\
\hline Negative & 31 & 68.9 & 15 & 33.3 & \\
\hline Positive & 14 & 31.1 & 30 & 66.7 & \\
\hline
\end{tabular}

H.Plori: Helicobacter pylori. 
Table (7): Association between the severity of PHG and H. Pylori.

\begin{tabular}{|l|c|c|c|c|c|}
\hline \multirow{2}{*}{} & \multicolumn{3}{|c|}{ With PHG } & \multirow{2}{*}{ P-value } \\
\cline { 2 - 5 } & \multicolumn{2}{|c|}{$\begin{array}{c}\text { Mild } \\
(\mathrm{n}=25)\end{array}$} & \multicolumn{2}{c|}{$\begin{array}{c}\text { Severe } \\
(\mathrm{n}=20)\end{array}$} & \\
\cline { 2 - 5 } & No. & $\%$ & No. & $\%$ & \\
\hline H. pylori & & & & & \multirow{2}{*}{0.012} \\
\hline Negative & 12 & 48 & 3 & 15 & \\
\hline Positive & 13 & 52 & 17 & 85 & \\
\hline
\end{tabular}

Table(8): Multi-variant analysis for prediction of PHG presence.

\begin{tabular}{|l|c|c|c|c|}
\hline \multicolumn{5}{|c|}{ Multi-Regression analysis: } \\
\hline & \multicolumn{7}{|c|}{ Dependent Variable: PHG } \\
\hline & Reg. Coef. & T & P & Sig. \\
\hline Item & -0.602 & -0.809 & 0.422 & NS \\
\hline (Constant) & 0.004 & 0.928 & 0.357 & NS \\
\hline Age & -0.062 & -0.584 & 0.561 & NS \\
\hline Jaundice & 0.018 & 0.128 & 0.898 & NS \\
\hline Abdominal enlargement & 0.068 & 4.52 & 0.000 & HS \\
\hline Splenomegaly & 0.104 & 0.78 & 0.439 & NS \\
\hline ascites Presence of & -0.013 & -0.719 & 0.475 & NS \\
\hline Hemoglobin & $3.626 \mathrm{E}-06$ & 0.004 & 0.997 & NS \\
\hline ALT & 0.001 & 1.327 & 0.190 & NS \\
\hline AST & 0.097 & 0.387 & 0.701 & NS \\
\hline Creatinine & 0.109 & 0.822 & 0.415 & NS \\
\hline Child classification & -0.015 & -0.483 & 0.631 & NS \\
\hline MELD & 0.019 & 0.053 & 0.958 & NS \\
\hline uMELD & -0.411 & -1.575 & 0.121 & NS \\
\hline Portal vein diameter & 0.218 & 4.413 & 0.000 & HS \\
\hline Esophageal varices & -0.141 & -2.141 & 0.037 & S \\
\hline Gastric Varices & -0.227 & -3.175 & 0.002 & HS \\
\hline Positivity of H.Pylori infection & P. & & & \\
\hline
\end{tabular}

RegCoef: regression coefficient, NS: non significant, S:significant, HS: highly significant.

\section{DISCUSSION}

Portal hypertensive gastropathy (PHG) is diagnosed by upper endoscopy characterized by a mosaic-like pattern or a diffuse, erythematous and reticular cobblestone pattern of gastric mucosa consisting of small polygonal areas with or without superimposed punctate red lesions and a depressed white border [10].

PHG develops as a consequence of portal hypertension which results in increasing gastric blood flow and congestion of mucosal and submucosal blood vessels leading to decrease of the mucous secretion and the local mucosal defense mechanism. Hence, the mucosa becomes susceptible to injurious agents such as nonsteroidal antiinflammatory drugs (NSAID) and H. Pylori infection $[\mathbf{1 1 , 1 2 ]}$. This study aimed to evaluate $\mathrm{H}$. pylori infection in patients with liver cirrhosis and to detect the association of $\mathrm{H}$. pylori infection with PHG and the severity of PHG.

The present study was conducted on 90 patients with liver cirrhosis. Patients were divided into two groups according to the presence of PHG. In this study, PHG was more common in males than in females, and this came in agreement with Abdul Sattar et al. [5] who mentioned that PHG was more frequent in males, and Bang et al. [13] who mentioned that male predominance was observed in the collected data for $78.7 \%$ of the PHG patients.

Regarding the age, the mean age was higher in patients with PHG with statistical significance, which came in agreement with Kiyono et al.[14] who mentioned that the PHG patients were significantly older than the non-PHG patients.

Ascites was more predominant in the PHG group than in the non-PHG group. These findings 
agreed with the results of Kumar et al. [15] and Mandhwani et al. [16] who showed a significant relation between PHG and presence of ascites, where ascites was more in cirrhotic patients with PHG.

Regarding the severity of liver disease assessed by Child Pugh score, most patients with PHG were of Child class B and Child class C, in contrast with the patients without PHG, whose majority were of Child class A. This agreed with Delisi et al. [17] who reported a significantly higher prevalence of PHG in Child-Pugh class B and $\mathrm{C}$ patients when compared to patients with Child class A, and with Tiwari et al. [10] who reported that the presence of PHG was significantly associated with Child-Pugh classification.

Regarding the severity of liver disease evaluated by MELD and UMELD scores, there was a statistically higher MELD and uMELD scores in patients with PHG, which came in accordance with Kim et al. [18] who showed that there was a significant relation between PHG and MELD scores. On the contrary, Eid et al. [4] showed that there was no statistically significant association between PHG and MELD scores, with mean score for PHG patients being 17.4 \pm 3.22 and for non-PHG patients being $16.7 \pm 1.94(\mathrm{P}=0.396)$. It also disagreed with Tiwari et al. [10] who reported that there was no significant association between MELD score and PHG. This could be due to limitations of MELD scoring system .

Regarding abdominal ultrasonographic findings, ascites was significantly more in patients with PHG group than in non-PHG group, agreed with Mandhwani et al.[16] who found that there is significant association of PHG and presence of ascites. Regarding to examination of spleen, the present study showed that the splenic size was significantly enlarged in PHG group which agreed with Kim et al. [18] who reported that the mean of spleen size was higher in cirrhotic patients with PHG. However, it disagreed with Nashaat et al.[19] who documented that there was no statistically significant correlation between PHG and splenic diameter. The portal vein was significantly dilated in PHG patients compared to those with non-PHG which agreed with Zardi et al. [20] who stated that the Portal vein was more dilated in cirrhotic patients with PHG, reflecting the increase in the portal venous pressure with subsequent formation of the gastric mucosal spots (gastropathy).
Concerning endoscopic findings in the present study, esophageal varices and gastric varices were significantly more predominant in patients with PHG than in patients without PHG, in accordance with Abbasi et al. [21] who reported that the presence of oesophageal varices had significant relation with $\mathrm{PHG}$, suggesting the presence of common pathophysiology for both of them. However, this disagreed with Tiwari et al.[10] who found that there was no association between the presence and esophageal varices and the presence of PHG. The variations in the results of the studies might be due to the fact that PHG is an objective diagnosis, consequently, there is interobserver variability. Moreover, many classifications for stratifying PHG severity. Most of the studies included unmatched groups of CLD, and others have included patients with portal hypertension caused by any causes other than cirrhosis.

This study showed that the large varices were more detected than small varices in patients with PHG, which agreed with Abbasi et al. [21] who reported that the PHG prevalence was higher in patients with large esophageal varices when compared to patients with small sized varices, and this might be due to sharing a common mechanism.

Concerning the relation of $\mathrm{H}$. pylori to $\mathrm{PHG}$, the present study showed that $\mathrm{H}$. Pylori infection was more frequent in patients with PHG (66.7\%) when compared to those without PHG (31.1\%), and this came in agreement with Safwat et al.[22] who detected that the prevalence of $\mathrm{H}$. Pylori infection was higher in patients with PHG in comparison to patients without PHG (69.2\% vs. $42.9 \%$; $\mathrm{p}=0.022$ ). Moreover, Abdul sattar et al.[5] detected that the presence of $\mathrm{H}$. pylori infection was found in 31(44.3\%) patients who had PHG when compared to 19 (27.1\%) patients without PHG. Hence, they concluded that there was a significant association between $\mathrm{H}$. pylori infection and PHG in patients with liver cirrhosis. Moreover, Eid et al.[4] reported that the prevalence of PHG was higher in PHG patients in comparison to those without (34 vs. $10 \%$ ), this is due to the gastric mucosa in case of cirrhosis, which might provide a good media for $\mathrm{H}$. pylori colonization, specifically when associated with swelling of the gastric mucosa and severe hemorrhagic congestion resulting in elevated inducible nitric oxid synthase (iNOS) expression, leading to increase reactive oxygen 
species and impaired defence mechanism of gastric mucosa due to PHG.

$\mathrm{Hu}$ et al. [23] found that the association between $\mathrm{H}$. Pylori and PHG is owing to the fact that gastric mucosa in PHG has thinner mucus and higher $\mathrm{pH}$ because of the decreased acid secretion and decreased prostaglandin, a protector of stomach, which eventually weakens the gastric barrier. Additionally, PHG has a lower resting gastric trans-mucosal potential difference that leads to decrease in intracellular $\mathrm{pH}$ among mucosal cells and the reduction of mucus and the weakness of the gastric mucosal barrier predisposing to mucosal lesions and resulting in suitable media for $\mathrm{H}$. pylori infection.

Regarding the relation between PHG severity and $\mathrm{H}$. pylori infection, $\mathrm{H}$. Pylori infection was significantly more frequent in patients with severe PHG than in those with mild PHG. This was in agreement with Hammad [24] who showed a significant association between $\mathrm{H}$. pylori infection and PHG severity, as H. pylori virulence factors induce the production of proinflammatory cytokines as tumor necrosis factor- $\alpha$, inducing mucosal inflammation and predispose to severity of PHG.

By multi-variant analysis for prediction of PHG presence, splenomegaly, presence of esophageal varices, gastric varices and $\mathrm{H}$. Pylori infection were significantly independent predictors for presence of PHG and this came in agreement with Eid et al. [4] who documented that there was a significant association between $\mathrm{H}$. pylori infection and PHG. Moreover, the splenic size was correlated significantly with presence of PHG in cirrhotic patients which agreed with Elwakil et al.[25] who mentioned that a complex relationship between PHG and presence of oesophageal varices (EV) has been observed in various studies. On one hand, new onset of PHG has been found to be associated with new onset or higher grade of EV. On the other hand, endoscopic obliteration of large grade varices and thus reduction in their size has been studied as a risk factor to endoscopic and pathologic deterioration of PHG.

\section{CONCLUSION}

H. Pylori infection was significantly associated with the presence of PHG and its severity. Presence of splenomegaly, esophageal varices
(EV), gastric varices and $\mathrm{H}$. pylori infection can independently predict the presence of PHG.

Acknowledgment: We would like to thank all colleagues who helped us in conducting this work.

\section{Funding: None}

\section{Conflict of interest: None}

Author contribution: All authors shared in conception of the idea, searching the literature, drafting the manuscript and all of them approved the final manuscript.

Ethical Approval: A written informed consent was taken from all included patients, and the study was approved by the Ethical Committee of our institution.

\section{REFERENCES}

1. Thuluvath P, Yoo H. Portal hypertensive gastropathy. Am J Gastroenterol 2002; 97: 29732978.

2. Urrunga NH, Rockey D. Portal hypertensive gastropathy and colopathy. Clin Liver Dis 2014; 18(2): 389-406.

3. Malatya H.M. Epidemiology of Helicobacter pylori infection. Best Pract Res Clin Gastroenterol 2007; 21: 205-214.

4. Eid KA, Shawky MA, Hassan AM, Mohammed AQ, Mohammed MI. Prevalence of Helicobacter pylori infection in patients with portal hypertensive gastropathy owing to liver cirrhosis in Upper Egypt. Al Azhar Assiut Med J 2016;14 (3):109-114.

5. Abdul Sathar S, Kunnathuparambil S.G, Sreesh S, Narayanan P, Vinayakumar K.R. Helicobacter pylori infection in patients with liver cirrhosis: prevalence and association with portal hypertensive gastropathy. Ann Gastroenterol 2014; 27(1): 48-52.

6. Pugh R.N, Murray-Lyon I.M, Dawson J.L, Pietrini M.C, Williams R. Transection of the esophagus for bleeding oesophageal varices. Br J Surg 1973; 60:646-649.

7. Kamath P.S, Wiesner R.H, Malinchoc M. A model to predict survival in patients with end-stage liver disease. Hepatology 2001; 33 (2): 464-70.

8. Sharma P, Shaubel D.E, Sima C.S. Re-weighting the model for end-stage liver disease score Components. Gastroenterology 2008;135: 15751581 . 
9. de Franchis R. Updating consensus in portal hypertension: report of the Baveno III Consensus Workshop on definitions, methodology and therapeutic strategies in portal hypertension. $J$ Hepatol. 2000;33(5):846-852.

10. Tiwari PS, Kc S, Sharma D, Paudel MS, Mandal A. Prevalence of Portal Hypertensive Gastropathy in Chronic Liver Disease and Correlation with the Severity of Liver disease. Cureus. 2019;11(8):e5454.

11. Perini RF, Camara PR, Ferraz JG. Pathogenesis of portal hypertensive gastropathy: translating basic research into clinical practice. Nat Clin Pract Gastroenterol Hepatol 2009; 6(3): 150-158.

12. Cestari R, Missale G, Cengia G, Minelli L Moneghini, D. Portal Hypertensive Gastropathy. Interventional and Therapeutic Gastrointestinal Endoscopy. Front Gastrointest Res. Basel, Karger, 2010, vol 27, pp 70-78.

13. Bang CS, Kim HS, Suk KT, Kim SE, Park JW, Park $\mathrm{SH}$, et al. Portal hypertensive gastropathy as a prognostic index in patients with liver cirrhosis. BMC Gastroenterol. 2016 Aug 12;16(1):93.

14. Kiyono S, Maruyama H, Kobayashi K, Kondo T, Sekimoto T, Shimada T, et al. Non-invasive diagnosis of portal hypertensive gastropathy: quantitative analysis of microbubble-induced stomach wall enhancement. Ultrasound in Med \& Biol 2016; pp. 1-8.

15. Kumar A, Mishra SR, Sharma P, Sharma BC, Sarin SK. Clinical, laboratory, and hemodynamic parameters in portal hypertensive gastropathy: a study of 254 cirrhotics. Journal of Clinical Gastroenterology 2010;44:294-300.

16. Mandhwani R, Hanif FM, Ul Haque MM, Wadhwa RK, Hassan Luck N, Mubarak M. Noninvasive Clinical Predictors of Portal Hypertensive Gastropathy in Patients with Liver Cirrhosis. J Transl Int Med. 2017;5(3):169-173.
17. De lisi S, Peralta S, Arini A, Simone F, Craxi A. Oesophagogastroduodenoscopy in patients with cirrhosis: Extending the range of detection beyond portal hypertension. Digestive and Liver Disease 2011; 43(1): 48-53.

18. Kim MY, Choi H, Baik SK, Yea CJ, Won CS, Byun JW, et al. Portal hypertensive gastropathy: correlation with portal hypertension and prognosis in cirrhosis. Dig Dis Sci. 2010;55:3561-3567.

19. Nashaat EH, Abd-Elaziz H, Sabry M, Ibrahim AA. Non-endoscopic predictors of esophageal varices and portal hypertensive gastropathy. Nature and Science. 2010;8(6):43-50.

20. Zardi EM, Ghittoni G, Margiotta D, Viera FT, Di Matteo F, Rossi S. Portal hypertensive gastropathy in cirrhotics without varices: a case-control study. Eur J Gastroenterol Hepatol. 2015;27:91-96.

21. Abbasi A, Bhutto AR, Butt N, Munir SM, Dhillo AK. Frequency of portal hypertensive gastropathy and its relationship with biochemical, haematological and endoscopic features in cirrhosis. J Coll Physicians Surg Pak. 2011; 21:723-726.

22. Safwat E, Hussein HA, Hakim SA. Helicobacter pylori in Egyptian patients with HCV-related liver cirrhosis and portal hypertensive gastropathy: Prevalence and relation to disease severity. Life Science Journal 2015; 12.(3):168-173.

23. Hu. JK, Li XM, Gu. BH, Zhang F, Li YM, Chen H. Helicobacter pylori and portal hypertensive gastropathy. Hepatobiliary Pancreatic Diseases International 2018; Dec;17(6):578-580.

24. Hammad, OM. Correlation of portal hypertensive gastropathy with Helicobacter Pylori infection, liver dysfunction, hypersplenism and oesophageal varices.Medical J Cairo Univ 2009;77:597-601.

25. Elwakil R, Al Breedy AM, Gabal HH. Effect of endoscopic variceal obliteration by band ligation on portal hypertensive gastroduodenopathy: endoscopic and pathological study. Hepatol Int 2016; 10(6):965-973. 